\title{
Cartilaginous metaplasia in giant fibrolipoma - a rare case report
}

\author{
Vyas K. C $C^{1}$, Wadhwan $G^{2}$, Agarwal $P^{3}$, Jain $S^{4}$, Sujanani $S^{5}$ \\ ${ }^{1}$ Dr. KC Vyas, Professor \& HOD, ${ }^{2}$ Dr. Gaurav Wadhawan, Assistant Professor, Department of Surgery, ${ }^{3}$ Dr. Preethi Agarwal, \\ Associate Professor, ${ }^{4}$ Dr. Suraj Jain, Assistant Professor, ${ }^{5}$ Dr. Shashi Sujanani, Professor \& HOD, Department of Pathology, \\ Pacific Medical College and Hospital (PMCH), Udaipur, Rajasthan, India.
}

Address for Correspondence: Dr. Suraj Jain, Assistant Professor, Email: bsurajjain@gmail.com

\begin{abstract}
The most common benign tumors of the mesenchyme are the lipomas. Lipomas can arise in any location in which fat is present. Different histopathological variants of lipoma have been described including fibrolipoma and chondrolipoma. Chondrolipoma is a rarely encountered diagnosis and is considered as a cartilaginous metaplasia in lipomas of large size. Given the rarity of this condition, we describe here a case of giant fibrolipoma with cartilaginous metaplasia in thigh of an elderly male patient.
\end{abstract}

Keywords: Fibrolipoma, Giant, Cartilaginous metaplasia

\section{Introduction}

Lipomas are benign, well circumscribed, connective tissue neoplasms. They usually present as slow growing, solitary and asymptomatic, subcutaneous or superficial lesions [1]. Most patients affected by lipomas are in their fifth or sixth decade of life, and only rarely are children affected [2]. Different variants of lipoma have been described, such as fibrolipoma, angiolipoma, myolipoma, spindle cell

\begin{abstract}
lipoma, chondroid lipoma, chondrolipoma and osteolipoma [1,3]. Fibrolipoma is characterized by the presence of prominent bundles of mature fibrous tissue traversing the fatty lobules [2]. Cartilaginous or osseous metaplasia (chondrolipoma and osteolipoma) is rare and is mainly encountered in lipomas of large size and long duration [3].
\end{abstract}

\section{Case Report}

A 59 year old male patient presented to the surgery department with history of swelling in the left thigh for last three years. Examination revealed a large mass in anterolateral aspect of left thigh, which was nontender, soft in consistency, noncompressible with well-defined margins. The swelling was not fixed to the skin or underlying structures. After the surgical resection of this mass, the histopathology section of ourlaboratory received a single well encapsulated fibrofatty tumor mass measuring $14 \times 12 \times 4 \mathrm{cms}$ and weighing about 640 grams. Cut surface of the mass was lobulated, yellow with myxoid appearing areas at places (Figure 1). The tumor mass was sliced in further parallel ways but no areas of hemorrhage or necrosis were noted. Multiple representative bits were taken from the tumor mass and processed conventionally for paraffin embedded tissue sections.

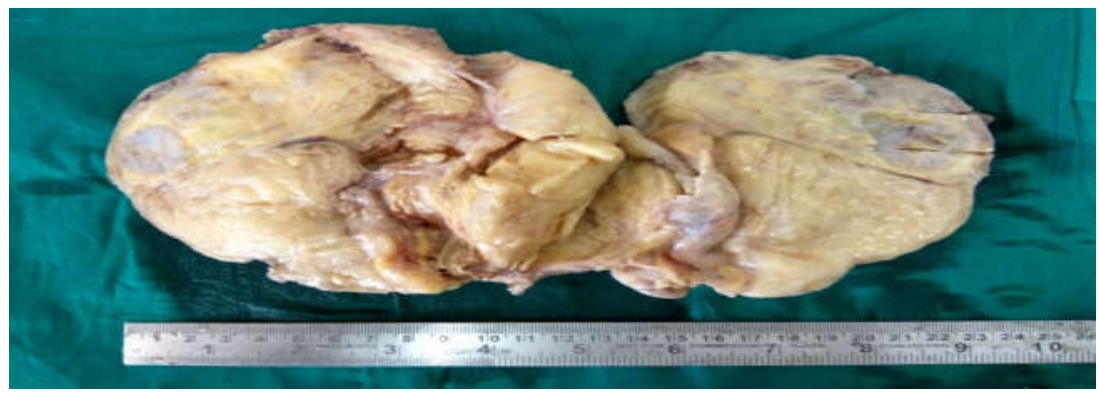

Figure-1: Cut surface of the mass was lobulated, yellow with myxoid appearing areas at places (Gross appearance)

Manuscript Received: $4^{\text {th }}$ September 2017

Reviewed: $14^{\text {th }}$ September 2017

Author Corrected: $21^{\text {st }}$ September 2017

Accepted for Publication: $28^{\text {th }}$ September 2017 


\section{Case Report}

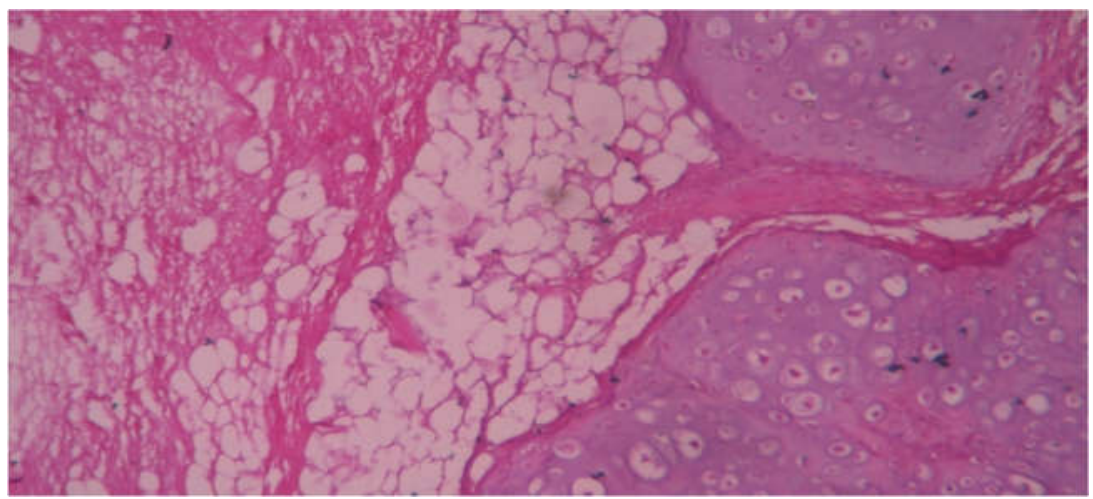

Figure-2: $H$ and $E$ stained sections showed admixture of mature adipocytes and spindle shaped cells along with islands of mature cartilage Microscopy (H\&E $40 \mathrm{x})$

Microscopically, $\mathrm{H}$ and $\mathrm{E}$ stained sections showed admixture of mature adipocytes and spindle shaped cells along with islands of mature cartilage (Figure 2). No areas of hemorrhage or necrosis were noted. No evidence of any malignant transformation was noted. These histopathological findings favoured a diagnosis of fibrolipoma with cartilaginous metaplasia.

\section{Discussion}

The etiology of lipomas is unclear. They have been reported to be both sporadic and inherited [4]. For a lipoma to be referred to as "giant", the lesion should be at least $10 \mathrm{cms}$ indiameter [2]. In our case, the lipoma was of $14 \times 12 \times 4 \mathrm{cms}$ in size. Fibrolipomas may develop in virtually any region that contains fat, but in general, they tend to appear on trunk, neck, and upper extremities. The fibrolipoma with cartilaginous metaplasia of our case was located in thigh.

Chondrolipoma is the mature adipocytic lesion displaying cartilaginous metaplasia (mature cartilage). It is an infrequent occurrence, which is predominantly observed in large-sized, long-standing lipomas [5]. The cartilaginous metaplasia observed in lipoma of our case was also of large size (14 cms in largest dimension) and of long-standing duration ( 3 years). There is a terminologically similar entity known as Chondroid lipoma. It is a benign adipose tissue tumour which contains a chondroid matrix, fat and lipoblasts. Both clinicians and pathologists should be aware of the terminological (but not histological) similarity between chondrolipomas and chondroid lipomas [6].

According to previous case reports, chondrolipomas arise mostly from the breast [7] or from head and neck region $[1,6]$. The occurrence in extremities is extremely rare and very few case reports of chondrolipoma are available to the best of our knowledge [5,8-10].

The malignant transformation of a lipoma into a liposarcoma is rare as is the sarcomatous transformation of giant lipomas. It is important to differentiate giant lipomas from liposarcomas, malignant fibrous histiocytoma and other benign soft tissue lesions [4]. Indeed, the main concern in the diagnosis of giant lipomas should be the exclusion of malignancy [2]. In our case after extensive sampling, the tumour mass revealed features of fibrolipoma with cartilaginous metaplasia. No evidence of any malignant transformation was noted.

\section{Conclusion}

Chondrolipomas are rare with very few cases reported in the literature. Being well demarcated in nature, makes them easily resectable by surgery and they do not recur. The additional presenceof giant fibrolipoma makes it a unique case report.

This case highlights the importance of extensive sampling in cases of giant lipomas to detect it's variants, associated metaplasias and to rule out malignancy.

Conflict of interest: None declared.

Funding: Nil, Permission from IRB: Yes

\section{References}

1. Raj V, Dwivedi N, Sah K, Chandra S. Chondrolipoma: Report of a rare intra oral variant with review of histiogenetic concepts. J Oral Maxillofac Pathol 2014 May; 18 (2):276-80. doi: 10.4103/0973-029X.140785.

2. Mazzocchi M, Onesti MG, Pasquini P, La Porta R, Innocenzi D, Scuderi N. Giant fibrolipoma in the leg--a case report. Anticancer Res. 2006 Sep-Oct; 26 (5B): 3649-54. 
3. Goldblum JR, Folpe AL, Weiss SW. Enzinger and Weiss's Soft tissue tumours. $6^{\text {th }}$ ed. Philadelphia:Elsevier Saunders; 2014: 443-483.

4. Gigis I, Gigis P. Fibrolipoma with Osseous and Cartilaginous Metaplasia of Hoffa's Fat Pad: A Case Report. Case Rep Orthop. 2012; 2012:547963. doi: 10. 1155/2012/547963. Epub 2012 Aug 2.

5. Boltze C, Hribaschek A, Lippert H, Roessner A. Intermuscular chondrolipoma of the thigh: the diagnostic way of a rare entity. Pathol Res Pract. 2003;199(7):503-7.

6. G K, Pj Y. Chondrolipoma of the lower lip: a case report. J Clin Diagn Res. 2014 Jun; 8 (6): FD07-8. doi: 10.7860/JCDR/2014/7634.4461. Epub 2014 Jun 20.
7. Banev SG, Filipovski VA. Chondrolipoma of the breast--case report and a review of literature. Breast. 2006 Jun; 15(3):425-6. Epub 2005 Aug 29.

8. Krüger S, Kisse B, Stahlenbrecher A, Feller AC, Hoch J. Chondrolipoma of the hand: a case report. Acta Orthop Belg. 2004 Oct;70(5):495-7.

9. Candocia FJ, Barlev DM. Chondrolipoma in the palm of a child: sonographic and MR findings. Clin Imaging. 2004 May-Jun;28(3):206-8.

10. Ito R, Fujiwara $M$, Takagaki $K$, Nagasako R. Chondrolipoma of the toe. J Dermatol. 2007 Aug; 34 (8): 570-2. doi: 10.1111/j.1346-8138.2007.00333.x

\section{How to cite this article?}

Vyas K. C, Wadhwan G, Agarwal P, Jain S, Sujanani S. Cartilaginous metaplasia in giant fibrolipoma - arare case report. Surgical Update: Int J surg Orthopedics. 2017;3(4):127-129.doi:10.17511/ijoso.2017.i04.06. 